\title{
Geophysical Engineering - Application of the geophysical methods of Electroresistivity and Spontaneous Potential in Tailings Dam monitoring
}

Omar Mendes de Melo Júnior ${ }^{\star 1}$, Luís Antônio Pinto e Almeida², Ricardo Luiz Teixeira Telles², Gilvan Sá2, Marco Antonio Braga $^{2},{ }^{1}$ UFRJ

Copyright 2021, SBGf - Sociedade Brasileira de Geofísica

This paper was prepared for presentation during the $17^{\text {th }}$ International Congress of the Brazilian Geophysical Society held in Rio de Janeiro, Brazil, 16-19 August 2021.

Contents of this paper were reviewed by the Technical Committee of the $17^{\text {th }}$ International Congress of the Brazilian Geophysical Society and do not necessarily represent any position of the SBGf, its officers or members. Electronic reproduction or storage of any part of this paper for commercial purposes without the written consent of the Brazilian Geophysical Society is prohibited.

\begin{abstract}
The disposal of tailings in dams is a frequent occurrence in mining companies, in view of the large volume of tailings generated by mining processes. Thus, for good safety management of these structures, constant inspections and monitoring are necessary. Such activities are carried out through direct and/or indirect measurements, by installed equipment (auscultation), visual inspection. Electrical resistivity and Spontaneos Potencial are a Geophysics branch that aims to investigate the subsurface properties and hydraulic dynamics of interpore fluids. The geophysics responses are get through the contrast between the physical properties of different materials. Due to the punctual nature of the auscultation measurements, these equipments may not show a region of unexpected saturation. Given the above, this study aims to present the effectiveness of the application of the geophysical methods, in a tailings dam located in the region of the Triângulo Mineiro in Minas Gerais state, through the identification of possibly saturated regions and possible percolations existing along the structure. In addition, a comparison was made with the geophysical results of 2018 , in order to monitor the structure over time.
\end{abstract}

\section{Introduction}

It is clear that the major challenge for the mining industry is to produce ore with the least possible environmental impact. Thus, new methods and technologies, such as geophysics, have been used in order to ensure the sustainability of operations and the safety of structures involved in mining activities, including tailings dams, pits and slopes.

These methods consists of a geological, structural, geomechanical and seismological investigation and monitoring of the environment in which the project is inserted.

In order to guarantee and ensure the integrity of the aforementioned structures, regular safety inspections are necessary, the frequency of which is established through the risks category and associated to potentials damages. In addition, monitoring through auscultation instruments is of fundamental importance for the geotechnical behavior of the structure.

Regular safety inspections aim to assess and monitor the main constituent elements of dams, as well as identify anomalies and changes that affect the integrity of these structures. Similarly, conventional monitoring, through instruments, consists of a set of equipment dispersed throughout of structure, in order to obtain information such as water level, pore pressure, displacement, precipitation and bottom drain flows. With these informations, it is possible to interpret the internal behavior, as well as verifying the functionality of the structure's internal drainage devices.

Even though conventional monitoring provides information about the geotechnical behavior of the structure, there are restrictions that must be taken into consideration, such as the fact that the analyzes are punctual and operational problems could be occur with these equipments. Thus, even with the correct visual security inspection and sufficiently instrumented, the structure has places where information and monitoring is unknown. It is in this perspective that geophysical methods find their application in geotechnics.

Geophysics is a branch of Geoscience that aims to investigate the properties of subsurfaces of the hydraulic structure through the contrast between the physical properties of materials. The analyzes are carried out in a non-invasive way, generating continuous images of the interior of the dam, making it possible to identify anomalies by conductive zones and flow paths. Furthermore, it significantly reduces the amount of instruments needed for conventional monitoring. Therefore, it is an economically interesting technology.

Due to the lack of knowledge and applicability, geophysical methods are not part of the traditional methodologies and procedures for geotechnical monitoring of tailings dams. Although used in countries such as Canada, Australia and the United States, the technique is relatively recent in Brazil. It is noteworthy that this method does not replace monitoring by auscultation instruments, however it allows a spatial assessment in 2D and $3 \mathrm{D}$ view models of the dams once calibrated with direct instrumentation.

In this work, electrical geophysical methods of electrical resistivity and spontaneous potential, carried out in two campaigns 2018 and 2020, were used to identify possible regions of moisture and percolation of the tailings dam. Figure 1 shows the location of the structure in question. 


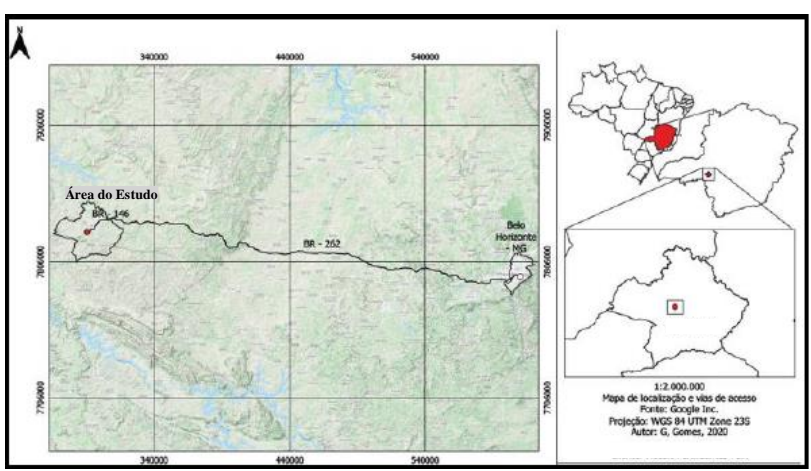

Figure 1 - Study area location map

\section{Method}

Geophysical methods have been shown to be of satisfactory use in subsurface prospecting, especially in detecting saturated zones and differentiating materials in containment structures. In this work, two electrical geophysical methods were used for data acquisition.

\section{Electrical resistivity Method}

Electrical resistivity aims to determine the variation of potencial differences represents a weighted avarege of all true resistivities in a subsurface material volume, through an artificial source of electrical current. The most used electro-resistivity technique is an electrical walking, as it is possible to identify variations in the structure's lateral and vertical resistivities. In this arrangement, artificial electrical currents are inserted into the ground through a pair of electrodes called A and B. The resulting potential differences are measured at points in the massif through another pair of electrodes, called $\mathrm{M}$ and $\mathrm{N}$, in the area of influence of the electric field (TELFORD et. al., 1990). The resistivity of soils and rock can be influenced by mineralogical composition, porosity, permeability, water content, presence of dissolved salts.

The data obtained are related through contour maps or sections of different depths. For data acquisition, the electrode arrangement must be defined, which is the geometric form in which they will be introduced into the ground, which can influence the sensitivity of data collection.

The profiles generated by the electric walking method allow investigation at depths of approximately 40.0 meters. The results obtained are consistent in the verification of high, low and intermediate resistivity anomalies. The analysis of the sections considers the differentiation of the profiles due to their magnitude in zones of high apparent resistivity (ZAR), zones of low apparent resistivity (ZBR) and zones of intermediate resistivity (ZIR). Conductive values can characterize regions with a higher probability of moisture in the central region and predominantly clayey materials. Figure 2 analysis the resistivity results in profile $X$, show the three geoelectrical zones mentioned.

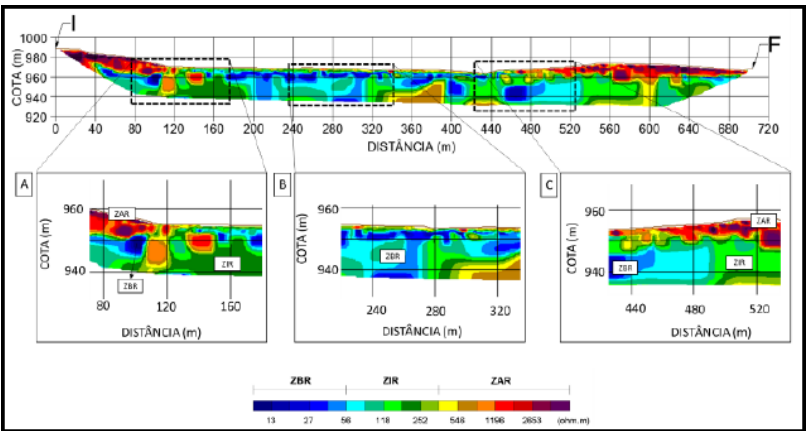

Figure 2-Geophysical profile with the differentiation of geoelectric zones.

\section{Spontaneous Potential Method}

The Spontaneous Potential, SP, is a passive geoelectric method of natural field. The application of the SP method for investigations of flows in tailings dams is based on measuring the potential stemming from the movement of water in a pore medium, in the process of electrofiltration (flow potentials). Water flow through a capillary system carries positive ions existing in the materials. Positive ions accumulate at the point capillary system, leaving a positive liquid charge. Ions untransported negatives accumulate at the entry point of the system leaving a negative charge. Groundwater flow, for example, is also an important agent for SP generation.

The interpretation of the acquired data is mainly qualitative and, in the case of potentials originating from water flow, when such anomalies are positive, they may indicate groundwater flow or water discharge areas. If negative, they may indicate areas of percolation. Figure 3 shows the result of the spontaneous potential survey through contour maps, which shows the spontaneous potential variation of the dam under study, indicating SP anomalies.

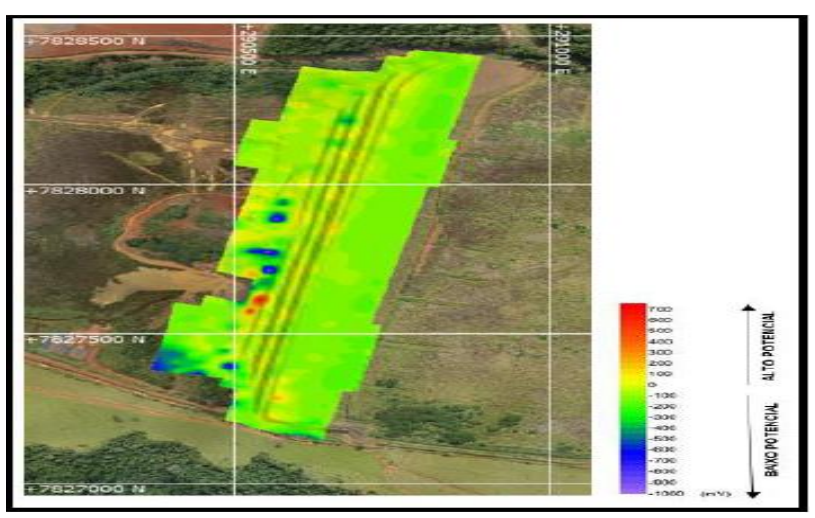

Figure 3 - Contour map using the dam spontaneous potential method.

The main advantage of the SP method is its simplicity, both instrumental and field operability. For an SP survey, you basically need two electrodes, a millivoltmeter and properly insulated wires for the connections between the electrodes.

There is a clear need to understand the application of the SP method in tailings dams, since concentrations of water flows in natural or artificial land can cause serious damage. Thus, systematic preventive monitoring or located in areas 
suspected of anomalous flows in the subsoil of the dam/slope can be very important.

\section{Results}

The geophysical surveys using electrical methods were carried out along the beach, massif and abutments of the tailings dam, located in the region of the Triângulo Mineiro in Minas Gerais state. The geophysical acquisitions were carried out in order to identify possible moisture regions and possible local percolations. Figure 4 shows the location of the sections carried out in the tailings dam.

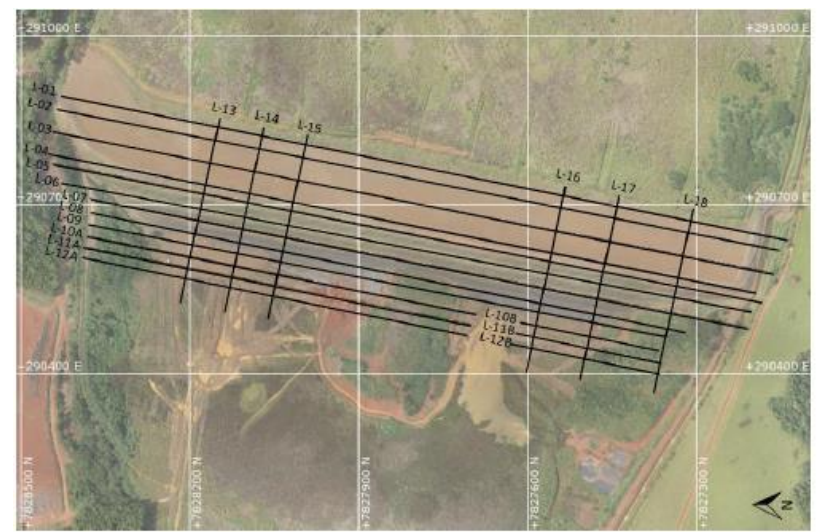

Figure 4 - Location of the Eletrical Resistivity ana Spontaneous Potential sections.

\section{Electrical Resistivity - Dipolo-Dipolo Array (Laying of cables)}

The Electrical Resistivity profiles allowed the verification at depths of up to 40 meters. The data collected were consistent in differentiating high, low and intermediate resistivity anomalies.

The analyzes of the geophysical sections considered the differentiation of the profiles due to their magnitude in Zones of Apparent High Resistivity (ZAR), whose values are above 371 ohm.m and Zones of Low Apparent Resistivity (ZBR), whose values are below 56 ohm.m and intermediate magnitudes were associated with Zones of Intermediate Resistivity (ZIR).

Figure 5 shows the resistivity scale normalized and adopted for geophysical analyses.

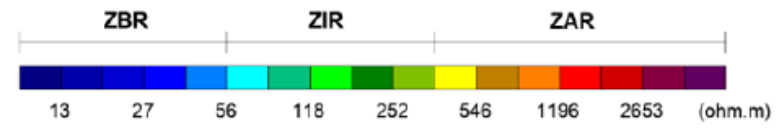

Figure 5- Normalized resistivity scale.

Due to the heterogeneity of the geophysical responses presented in the sections, they were grouped into different groups as a way to assist in their descriptions.

Group 01

Group defined by the sections located in the tailings beach region of Dam, as shown in Figure 6.

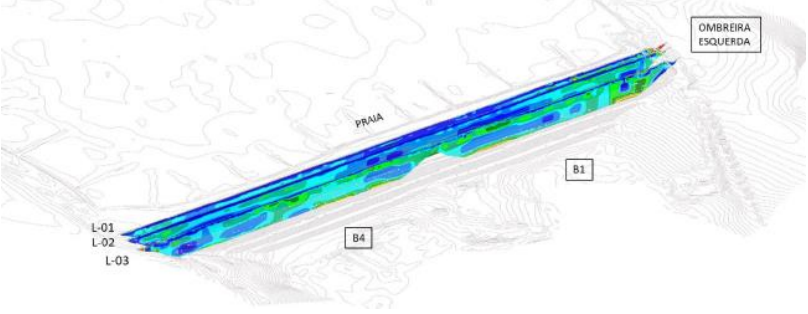

Figure 6 - Location of the Electrical resistivity sections belonging to Group 1.

The sections are characterized, in general, by the predominance of low apparent resistivity values. It is observed, in the most superficial portions of the sections, a certain concentration of lower apparent resistivity values. There are more resistive portions that appear anomalously arranged, especially in the basal portions of these sections. Figure 7 presents a geophysical section highlighting the main zones.

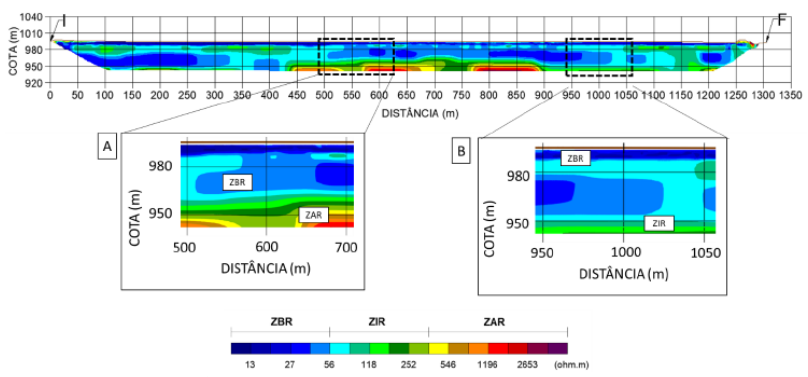

Figure 7 - Characterization of geophysical zones of section L-02 of Group 1.

\section{Group 02}

The sections of this group are located in the dam central region and abutment region and are presented according to Figure 8.

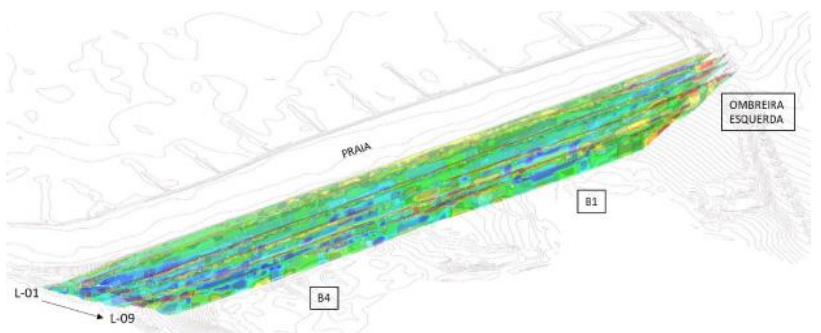

Figure 8 - Location of Electrical resistivity sections belonging to Group 2.

The sections showed less evidence and expression of low apparent resistivity (ZBR) values. In the more superficial portions, there was a relative concentration of higher apparent resistivity values (ZIR and/or ZAR), continuously arranged throughout the region, as shown in Figure 9. 


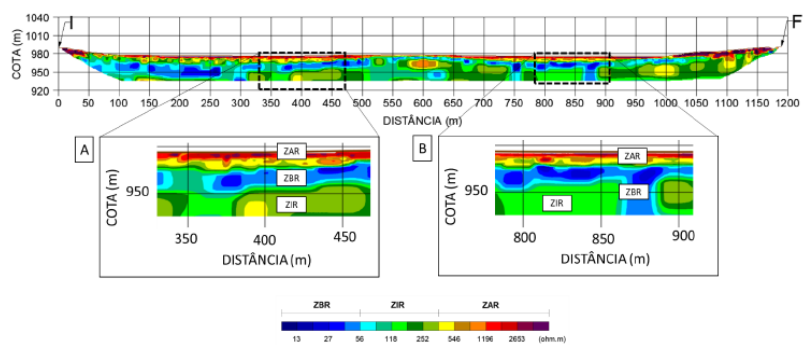

Figure 9 - Characterization of geophysical zones of section L-07 of Group 2.

\section{Group 03}

This group is composed of sections located downstream of the structure, as seen in figure 10.

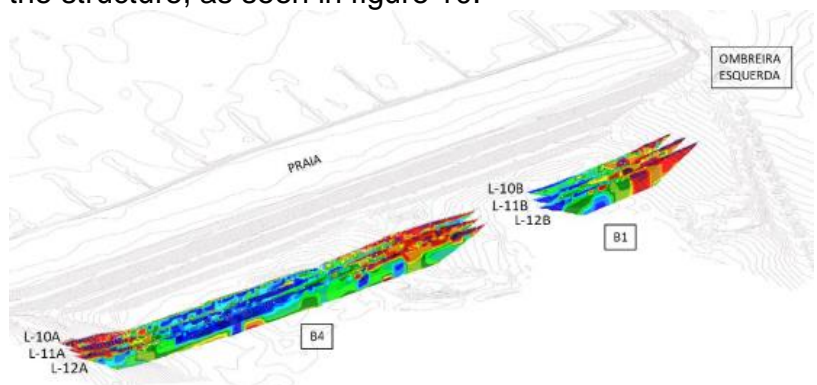

Figure 10 - Location of Electrical Resistivity sections from Group 3.

The sections are characterized by a subsurface horizon that varies from conductive (ZBR) to intermediate (ZIR) values. Below this layer, there is a largely conductive region that, in depth, changes to a region with a tendency to an increase in the apparent resistivities values (ZAR and ZIR), as illustrated in figure 11.
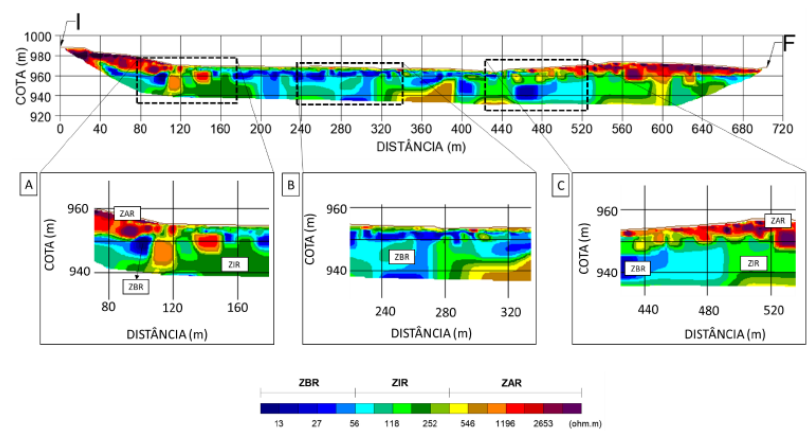

Figure 11 - Characterization of geophysical zones of the L-10A section of Group 3.

Group 04

The sections were distributed perpendicularly to the dam, according to figure 12 .

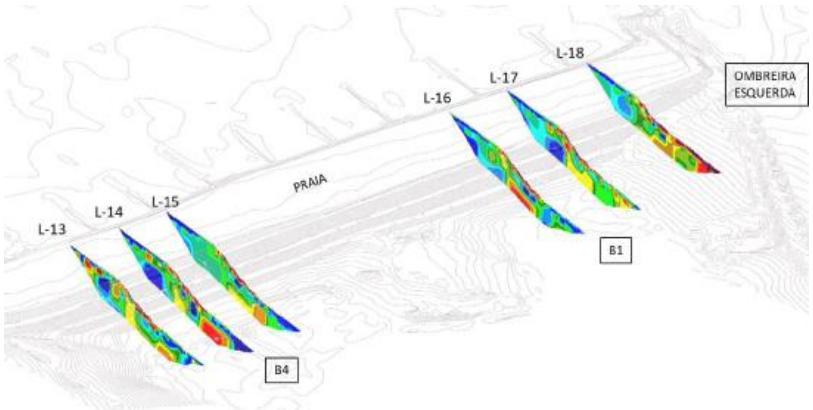

Figure 12 - Location of Electrical resistivity differences belonging to Group 4.

This Group is characterized by a conductive surface horizon (ZBR), which extends in depth into the initial portions of the geophysical profiles. The central region of the sections is characterized by a resistive subsurface horizon superimposed on a conductive region. The downstream portion of the dam is characterized by low resistivity values, with the exception of the L-18 profile, as it is a region of natural terrain, as illustrated in figure 13.

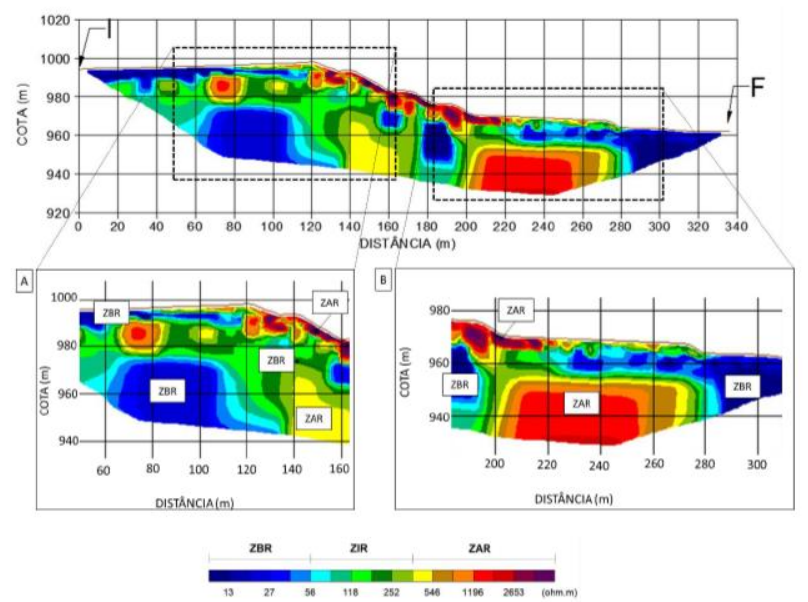

Figure 13 - Characterization of geophysical zones of section L-14 of Group 4.

\section{Spontaneous Potential (SP)}

The results of the Spontaneous Potential (SP) surveys are presented in the Potential Map as shown in figure 14.

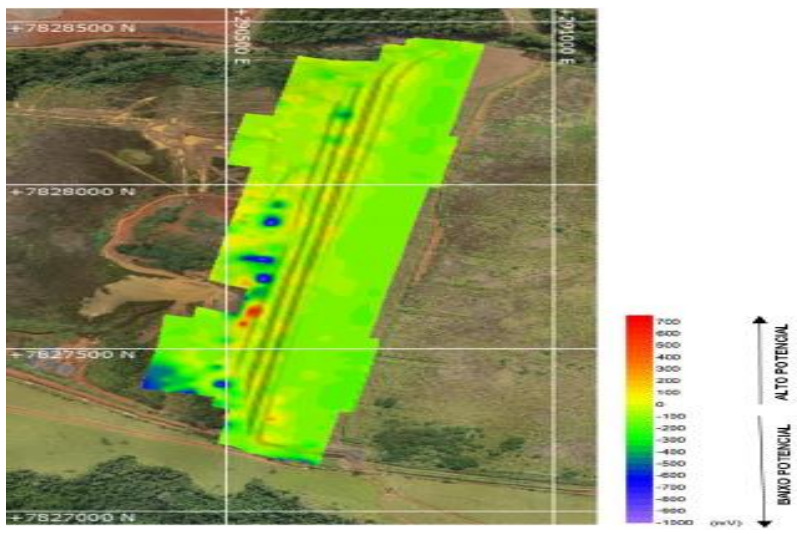

Figure 14-Map of Potentials generated by the SP at Dam. 
The analyzed data showed the presence of two behavior patterns: low potentials (cold, bluish tones, with values from $-1000 \mathrm{mV}$ to $0 \mathrm{mV}$ ) and high potentials (warm, reddish tones, with values from $0 \mathrm{mV}$ to $+700 \mathrm{mV}$ ).

The generated Potential Map is characterized by a homogeneous pattern with low potential values in the portion belonging to the tailings beach. Towards the dam massif, there is an increase in potential values.

On the other hand, downstream of the dam, it is possible to observe punctual anomalies of both high potential and low natural potential. It is also possible to observe a concentration of low potentials located in the downstream region of the structure near the left abutment.

\section{Conclusions}

According to this study, it is concluded the great applicability, importance and effectiveness in the use of geophysics in the monitoring of tailings dams, as it was possible to determine and identify the different constituent materials of the dam, such as the standing drain and the drainage mat, and through from the comparison between the 2018 and 2020 geophysics acquisitions, a reduction in the low resistivity zones in the downstream portions of the structure was evidenced.

\section{References}

BARBOSA, O.; BRAUN, O. P. G.; DYER, R. C.; CUNHA, C. A. B. R. 1970. Geologia da região do Triângulo Mineiro. Rio de Janeiro. DNPM/DFPM, 140 p.

BARKER, R. D. 1989. Depth of investigation of collinear symmetrical four-electrode arrays. Geophysics, v. 54, n. 8, p. 1031-1037.

BOGOSLOVSKY, V. A \& OGILVY, A. A. 1970a. Application of geophysical methods to studying the technical status of earth dams. Geophysical Prospecting, 758-773 p.

BOGOSLOVSKY, V. A \& OGILVY, A. A. 1970b. Natural potential anomalies as a quantitative index of seepage from water reservoirs. Geophysical Prospecting, 261-268 p.

BOGOSLOVSKY, V. A \& OGILVY, A. A. 1973a. Eletrometric observations of antifiltrational cementation curtains. Geophysical Prospecting, 296-314 p.

BOGOSLOVSKY, V. A \& OGILVY, A. A. 1973b. Deformations of natural field near drainage structures. Geophysical Prospecting, 716-723 p.

GALLAS, J. D. F. 2005. O método do Potencial Espontâneo (SP) - Uma revisão sobre suas causas, seu uso histórico e suas aplicações atuais. Revista Brasileira de Geofísica, 23(2): 133-144 p.

PELLERIN, L. 2002. Applications of Electrical and Electromagnetic Methods for Environmental and Geotechnical Investigations. Surveys in Geophysics, 23, 101-132.

ROY, A.; APPARAO, A. 1971. Depth of investigation in direct current methods. Geophysics, v. 36, n. 5, 943-959 p.

SEER, H. J.; MORAES, L. M.; SILVA, C. H. 2015. Geologia da Folha Araxá, escala 1: 100.000. Belo Horizonte,
CODEMIG - Companhia de Desenvolvimento Econômico de Minas Gerais.

SIMÕES, L. S. A.; NAVARRO, G. 1996. Estruturação da Faixa Brasília na região de Araxá-MG. Anais do XXXIX Congresso Brasileiro de Geologia. Salvador. SBG, v.6, 92$95 \mathrm{p}$. 